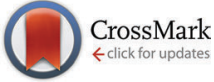

Cite this: Chem. Commun., 2015 51, 12992

Received 4th June 2015 Accepted 2nd July 2015

DOI: $10.1039 / \mathrm{c5cc04589d}$

www.rsc.org/chemcomm

\section{Ruthenium- and palladium-catalyzed consecutive coupling and cyclization of aromatic sulfoximines with phenylboronic acids: an efficient route to dibenzothiazines $\dagger$}

\author{
Ravi Kiran Chinnagolla, Arjun Vijeta and Masilamani Jeganmohan*
}

\begin{abstract}
A ruthenium-catalyzed ortho arylation of aromatic sulfoximines with aromatic boronic acids followed by intramolecular cyclization in the presence of a palladium catalyst, providing dibenzothiazine derivatives in two consecutive steps, is described.
\end{abstract}

Sulfoximine is a pivotal structural motif which is present in various biologically active molecules, pharmaceuticals and agrochemicals (eqn (1)). ${ }^{1}$ The sulfoximine derivatives are also successfully used as chiral auxiliaries and ligands in asymmetric synthesis of various chiral organic molecules. ${ }^{2}$ Several methods are available in the literature to synthesize linear sulfoximine derivatives. ${ }^{3}$ But, the synthesis of cyclic sulfoximines is limited in the literature. ${ }^{4}$ Recently, the synthesis of cyclic sulfoximines has gained much attention in organic synthesis due to their usefulness as scaffolds in drug development and as chiral ligands in enantioselective reactions. ${ }^{5}$ Meanwhile, sulfoximine derivatives also serve as key synthetic intermediates in various organic transformations. ${ }^{5-7}$
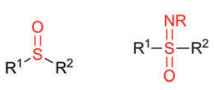

Sulfoxide

Sulfoximine

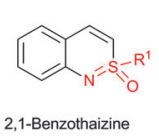

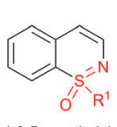

1,2-Benzothaizine

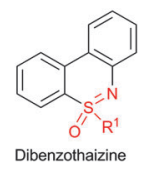

Harmata's group reported the synthesis of bicyclic sulfoximine derivatives such as 1,2-benzothiazine and 2,1-benzothiazine by palladium-catalyzed cyclization of 2-bromo benzaldehydes or 2-alkenylated aromatic bromides with sulfoximines, $\mathrm{AlCl}_{3}$-mediated cyclization of sulfonimidoyl chlorides with alkynes or alkenes and electrophilic cyclization of 2-bromophenyl substituted sulfoximines with terminal alkynes in the presence of palladium and copper catalysts. ${ }^{6}$ Very recently, Bolm's group reported the synthesis of bicyclic 1,2-benzothiazine derivatives via rhodiumcatalyzed oxidative cyclization ${ }^{7 a}$ of phenyl sulfoximines with

Department of Chemistry, Indian Institute of Science Education and Research,

Pune 411021, India. E-mail: mjeganmohan@iiserpune.ac.in

$\dagger$ Electronic supplementary information (ESI) available: Detailed experimental procedures and spectroscopic data. See DOI: 10.1039/c5cc04589d alkynes via a chelation-assisted $\mathrm{C}-\mathrm{H}$ bond activation reaction. ${ }^{8-10}$ Subsequently, sulfoximine directed ortho alkenylation of phenyl sulfoximines with alkenes in the presence of a metal catalyst was also disclosed. ${ }^{7 b-e}$ In all these reports, sulfoximine containing bicyclic benzothiazine derivatives were synthesized efficiently.

Herein, we report the synthesis of tricyclic dibenzothiazines by a ruthenium-catalyzed ortho arylation of phenyl sulfoximines with aromatic boronic acids followed by intramolecular cyclization in the presence of a palladium catalyst in two consecutive steps. The present reaction was compatible with various sensitive and useful functional group substituted phenyl sulfoximines and aromatic boronic acids. An enantioselective version of ortho arylation of phenyl sulfoximines with phenylboronic acids followed by cyclization, and this transformation leads to chiral dibenzothiazines with an excellent ee ratio of $99 \%$.

Initially, the ortho arylation of phenyl sulfoximine (1a) with phenylboronic acid (2a) (1.5 equiv.) in the presence of $\left[\left\{\mathrm{RuCl}_{2}\right.\right.$ ( $p$-cymene $\left.)\}_{2}\right]$ (5 mol\%), $\mathrm{AgSbF}_{6}(20 \mathrm{~mol} \%)$ and $\mathrm{Cu}(\mathrm{OAc})_{2} \cdot \mathrm{H}_{2} \mathrm{O}$ (1.5 equiv.) in $\mathrm{THF}$ at $100{ }^{\circ} \mathrm{C}$ for $16 \mathrm{~h}$ was investigated (Scheme 1). In the reaction, $N$-arylated phenyl sulfoximine $\mathbf{3 a}$ in $35 \%$ yield, mono ortho arylated phenyl sulfoximine 4 a in $5 \%$ yield and bis ortho arylated phenyl sulfoximine 5a in $15 \%$ yield were observed, respectively (Scheme 1). It is known that the free $\mathrm{N}-\mathrm{H}$ group of $\mathbf{1 a}$ is acidic in nature and smoothly undergoes $\mathrm{N}$-arylation with aromatic electrophiles or organometallic reagents

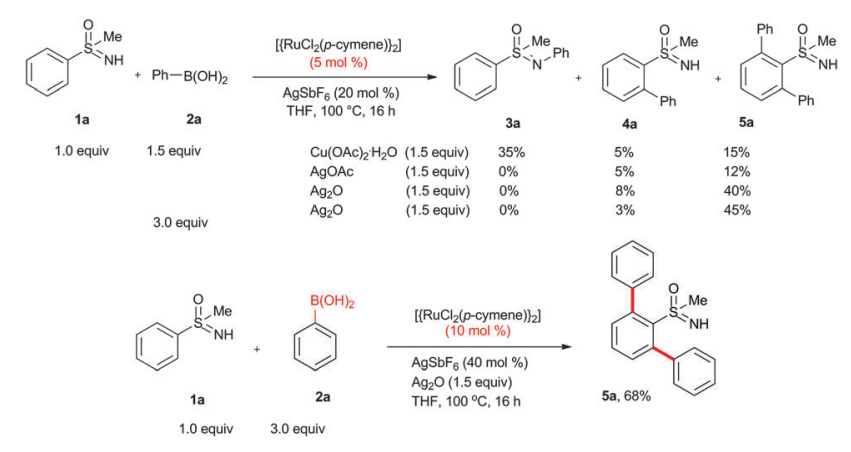

Scheme 1 ortho Arylation of sulfoximine $\mathbf{1 a}$ with $\mathbf{2 a}$. 
providing $N$-arylated sulfoximines 3 in the presence of metal catalysts. ${ }^{11}$ To successfully carry out the ortho arylation reaction, the suppression of product $\mathbf{3}$ is highly important. Next, the reaction was tested with other oxidants and acetate sources such as AgOAc, NaOAc, $\mathrm{K}_{2} \mathrm{CO}_{3}$, CsOAc and $\mathrm{Ag}_{2} \mathrm{O}$. Among them, silver salts such AgOAc and $\mathrm{Ag}_{2} \mathrm{O}$ were active for the reaction and no $\mathrm{N}$-arylated product 3a was observed. In AgOAc, product 4a in 5\%

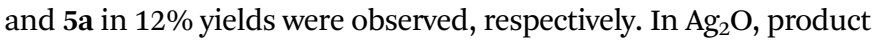
4a in $8 \%$ and 5 a in $40 \%$ yields were observed, respectively. Other acetate sources were not active for the reaction. Next, the coupling reaction was tested with an excess amount of phenylboronic acid 2a (3.0 equiv.). In the reaction also, a mixture of products $4 \mathbf{4 a}$ and 5a were observed in $3 \%$ and $45 \%$ yields, respectively. To increase the yield of $\mathbf{5 a}$, the coupling reaction was performed in the presence of $10 \mathrm{~mol} \%$ of catalyst and $40 \mathrm{~mol} \%$ of $\mathrm{AgSbF}_{6}$. Interestingly, in the reaction, only bis ortho arylated product 5 a was observed in $68 \%$ isolated yield and no mono arylated product $\mathbf{4 a}$ was observed. For the detailed optimization studies, please see ESI. $\dagger$

In addition to phenylboronic acid (2a), a wide range of aromatic boronic acids $\mathbf{2 b}-\mathbf{j}$ also readily participates in the reaction with 1a. Table 1 summarizes the results of these reactions. Treatment of 4-phenyl substituted phenylboronic acid (2b) with 1a provided ortho bis arylated product 5ab in $72 \%$ yield (entry 1). Electron rich 4-methoxyphenyl boronic acid (2c) reacts smoothly with 1a, yielding the corresponding product 5 ac in $66 \%$ yield (entry 2). Aromatic boronic acids having halogen groups $\mathrm{I}, \mathrm{Br}, \mathrm{Cl}$ and $\mathrm{F} \mathbf{2 d - g}$ also undergo an ortho arylation reaction with 1a efficiently, giving products 5 ad-ag in $65 \%$, $62 \%, 64 \%$ and $60 \%$ yields, respectively (entries 3-6). However, 3-bromo phenylboronic acid (2h) yielded product 5ah only in 19\% yield (entry 7). Benzo[d][1,3]dioxol-5-ylboronic acid (2i) and 2-naphthylboronic acid (2j) also efficiently participated in the reaction, affording coupling products 5ai and 5aj in 61\% and $64 \%$ yields, respectively (entries 8 and 9).

The arylation reaction was examined with substituted aromatic sulfoximines 1b-g (Scheme 2). Electron-rich, halogen and electrondeficient group substituted sulfoximines were compatible for the reaction. Methyl, $\mathrm{Br}$ and $\mathrm{NO}_{2}$ substituted sulfoximines 1b-d reacted with 2 a, providing products 5 ba-da in $65 \%, 63 \%$ and $54 \%$ yields, respectively. Similarly, $\mathrm{Cl}$ and $\mathrm{F}$ substituted aromatic sulfoximines 1e-f reacted with $\mathbf{2 c}$, providing products 5ec-fc in $60 \%$ and $63 \%$ yields, respectively. Likewise, (ethylsulfonimidoyl)benzene (19) afforded $5 \mathrm{ga}$ in $71 \%$ yield.

Apart from bis arylation, mono arylation of phenyl sulfoximines was also disclosed (Scheme 3). Treatment of 2-methyl phenylsulfoximine (1h) with $\mathbf{2 a}$ or $\mathbf{2 f}$ gave mono arylated sulfoximine derivatives 5 ha and 5 he in $70 \%$ and $63 \%$ yields, respectively. However, 3-methyl phenylsulfoximine (1i) afforded regioisomeric mono arylated products $5 \mathbf{i a}$ and $5 \mathbf{i a} \mathbf{a}^{\prime}$ in $62 \%$ and $7 \%$ yields, respectively.

Next, we tried to couple the $\mathrm{N}-\mathrm{H}$ bond of sulfoximine with one of the $\mathrm{C}-\mathrm{H}$ bond of phenyl groups of compound 5 via chelation-assisted remote $\mathrm{C}-\mathrm{H}$ activation in order to prepare tricyclic dibenzothiazine derivatives. A $\mathrm{Pd}(\mathrm{OAc})_{2}$ catalyst along with an oxidant is the suitable condition for this type of cyclization. $^{7 c, 12}$ The intramolecular cyclization of compound 5aa
Table 1 Ruthenium-catalyzed ortho arylation of $1 \mathrm{a}$ with aromatic boronic acids $\mathbf{2} \mathbf{b}-\mathbf{j}^{\mathrm{a}}$

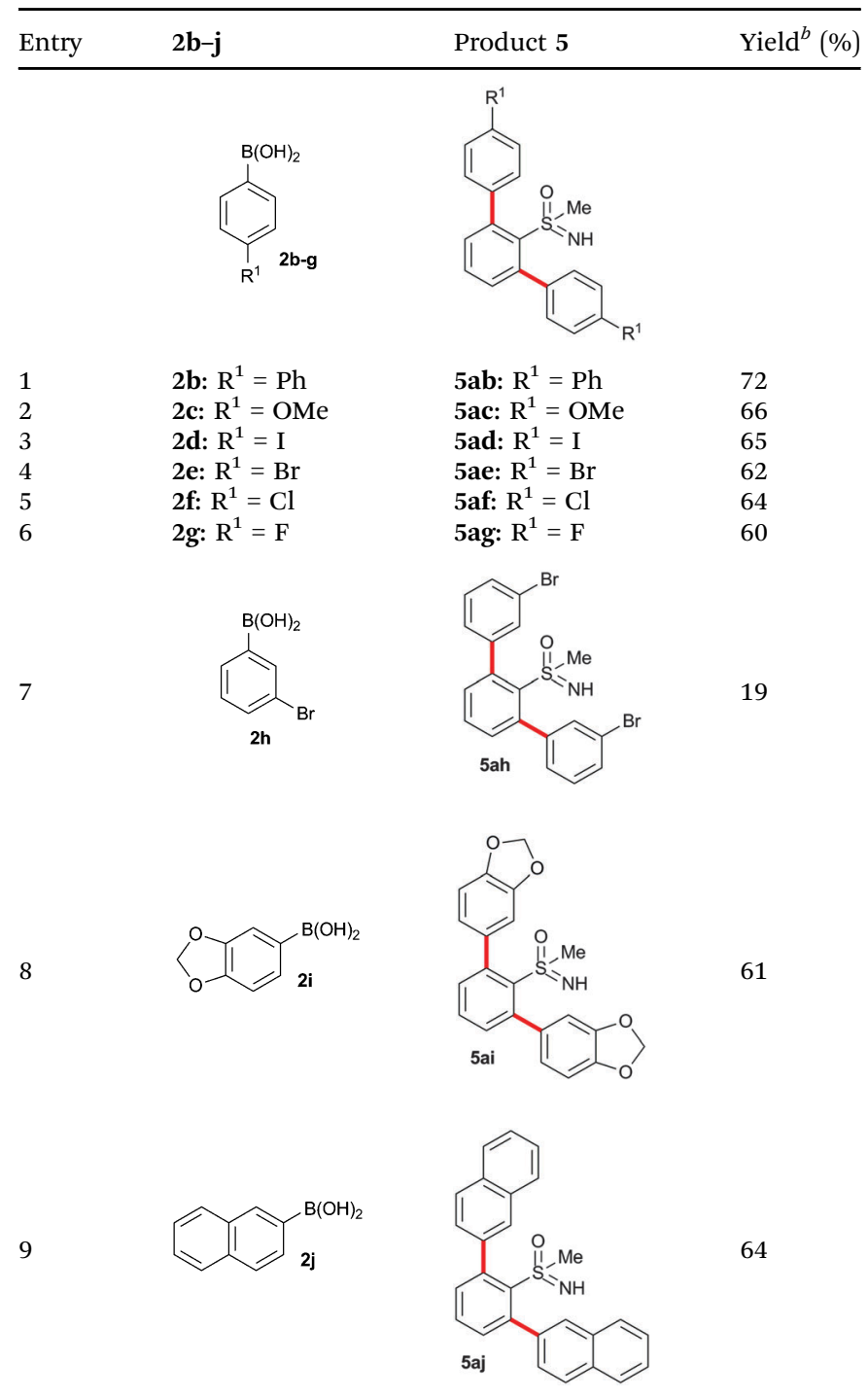

${ }^{a}$ All reactions were carried out using $\mathbf{1 a}(100 \mathrm{mg})$, aromatic boronic acids (2b-j) (3.0 equiv.), $\left[\left\{\mathrm{RuCl}_{2}(p \text {-cymene })\right\}_{2}\right]$ (10 mol\%), $\mathrm{AgSbF}_{6}(40 \mathrm{~mol} \%), \mathrm{Ag}_{2} \mathrm{O}$ (1.5 equiv.) in THF $(3.0 \mathrm{~mL})$ at $100{ }^{\circ} \mathrm{C}$ for 16 h. ${ }^{b}$ Isolated yield.

proceeded smoothly in the presence of $\mathrm{Pd}(\mathrm{OAc})_{2}(10 \mathrm{~mol} \%)$ and $\mathrm{PhI}(\mathrm{OAc})_{2}$ (2.0 equiv.) in toluene at $120{ }^{\circ} \mathrm{C}$ for $10 \mathrm{~h}$ giving a tricyclic dibenzothiazine derivative $\mathbf{6 a}$ in $76 \%$ yield (Table 2 , entry 1 ). The cyclization reaction also proceeded in the presence of $\mathrm{PhI}(\mathrm{OAc})_{2}$ without a palladium catalyst. However, product $6 \mathbf{a}$ was observed in a less amount of $25 \%$ yield. Under similar reaction conditions, products 5ab, 5ac, 5ad, 5ae, 5af and 5ag also efficiently participated in the reaction, providing cyclization products $\mathbf{6 b}-\mathbf{g}$ in good to excellent yields (entries 2-7). Similarly, products 5ba, 5ca, 5da, 5ga and 5ha afforded dibenzothiazines 6h-1 in 80\%, 84\%, 79\%, $83 \%$ and $41 \%$ yields, respectively (entries $8-12$ ). The structure of compound 6 f was further confirmed by single crystal X-ray analysis (see ESI $\dagger$ ).

This result prompted us to explore the possibility of synthesis of chiral tricyclic dibenzothiazines by using chiral phenyl 


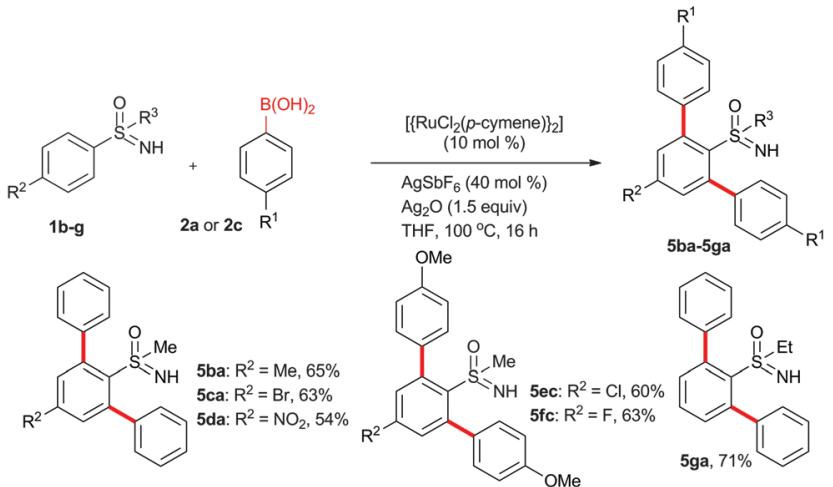

Scheme 2 Scope of aromatic sulfoximines.

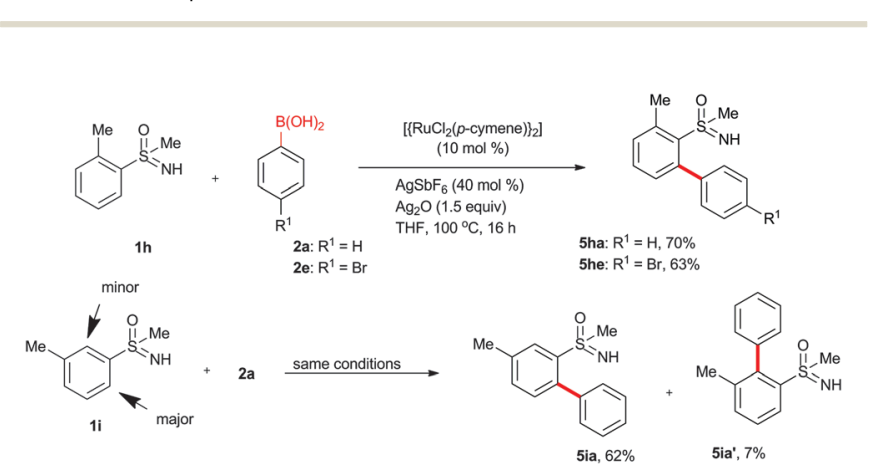

Scheme 3 Mono arylation of aromatic sulfoximines $\mathbf{1 h}-\mathbf{i}$.

sulfoximines 7a-b (Scheme 4). Treatment of chiral $(R)-(-)-S$ methyl-S-phenylsulfoximine (7a) with substituted phenyl boronic acids $2 \mathbf{2 a}, \mathbf{2 d}, \mathbf{2 f}$ and $2 \mathbf{g}$ in the presence of $\left[\left\{\mathrm{RuCl}_{2}(p \text {-cymene })\right\}_{2}\right]$, $\mathrm{AgSbF}_{6}$ and $\mathrm{Ag}_{2} \mathrm{O}$ in THF at $100{ }^{\circ} \mathrm{C}$ for $16 \mathrm{~h}$ gave chiral ortho arylated phenyl sulfoximines 7 aa-ag in $65 \%, 63 \%, 60 \%$ and $62 \%$ yields, respectively (Scheme 4). Interestingly, the enantiomeric excess (ee) of products 7aa-ag did not drop and in all cases $>99 \%$ ee ratios were observed. Later, compounds $7 \mathbf{a a}-\mathbf{a g}$ were cyclized into chiral dibenzothiazines 8a-d in excellent $74 \%, 73 \%$, $75 \%$ and $79 \%$ yields, respectively, in the presence of a palladium catalyst. In all these reactions, $>99 \%$ ee ratios were observed. Furthermore, $(S)-(-)-S$-methyl-S-phenylsulfoximine (7b) underwent ortho arylation with aromatic boronic acids $2 \mathbf{a}, 2 \mathbf{b}$ and $2 \mathbf{e}$ in the presence of a ruthenium catalyst, providing chiral ortho arylated phenyl sulfoximines 7 ba-be in $67 \%, 65 \%$ and $61 \%$ yields, respectively, with $>99 \%$ ee ratios. Furthermore, 7 ba-be were converted into chiral dibenzothiazines $\mathbf{8 e - \mathbf { g }}$ in the presence of $\mathrm{Pd}(\mathrm{OAc})_{2}$ in $72 \%, 82 \%$ and $83 \%$ yields, respectively.

A possible reaction mechanism is proposed to account for the present reaction in Scheme 5. Two different catalytic reactions were involved in the reaction. In the first catalytic cycle, $\mathrm{AgSbF}_{6}$ likely removes all $\mathrm{Cl}^{-}$ligands from the ruthenium complex providing a cationic ruthenium complex $9 .^{13}$ Coordination of the nitrogen atom of sulfoximine $\mathbf{1}$ into catalyst $\mathbf{9}$ followed by ortho-metalation provides a ruthenacycle intermediate 10. Transmetallation of phenyl boronic acid 2 into intermediate 10 in the presence of $\mathrm{Ag}_{2} \mathrm{O}$ affords intermediate 11. Subsequent reductive elimination of intermediate $\mathbf{1 1}$ in the presence of $\mathrm{Ag}^{+}$source provides product 5 and regenerates the
Table 2 Synthesis of dibenzothiazines ${ }^{a}$

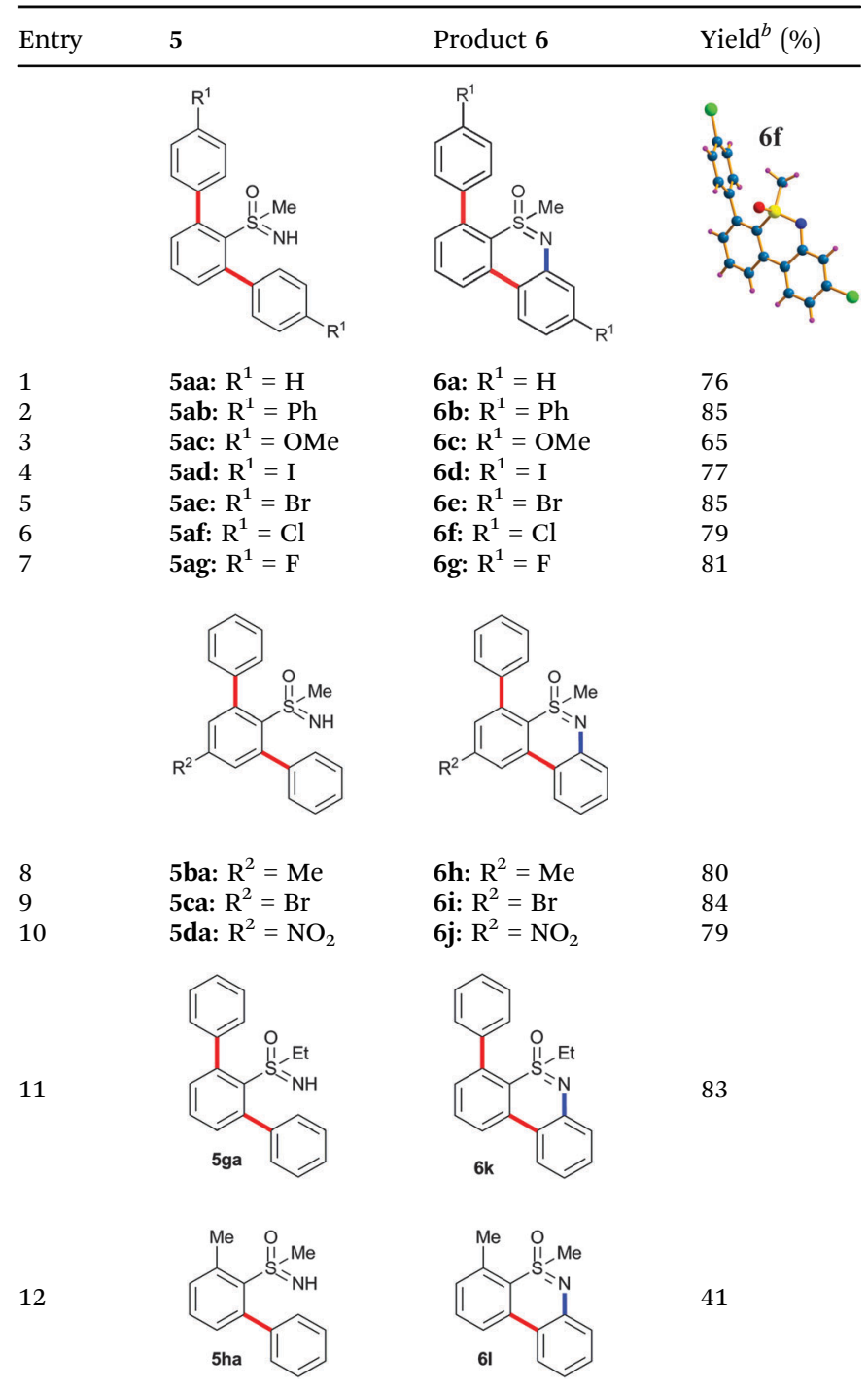

${ }^{a}$ All reactions were carried out using $5(100 \mathrm{mg}), \operatorname{Pd}(\mathrm{OAc})_{2}(10 \mathrm{~mol} \%)$ and $\mathrm{PhI}(\mathrm{OAc})_{2}$ (2.0 equiv.) in toluene at $120{ }^{\circ} \mathrm{C}$ for $10 \mathrm{~h} .{ }^{b}$ Isolated yield.

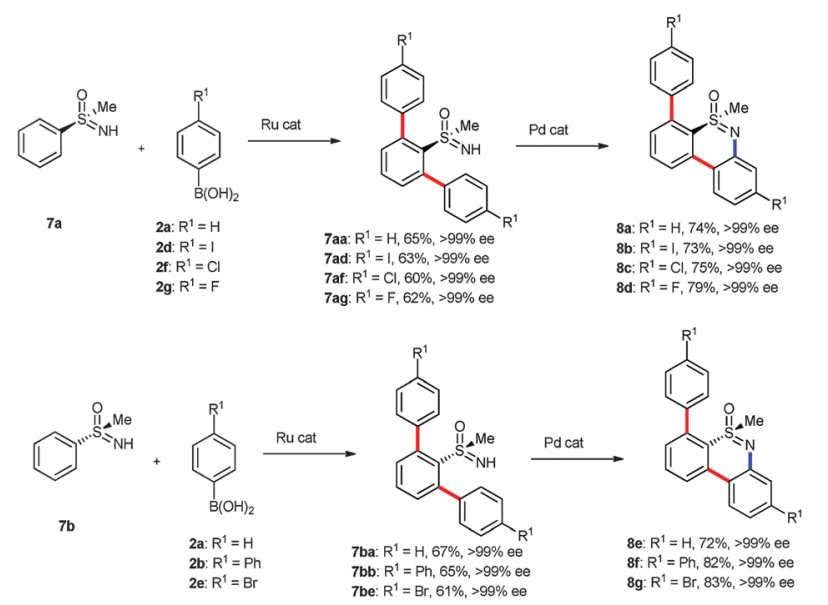

Scheme 4 Synthesis of chiral dibenzothiazines. 


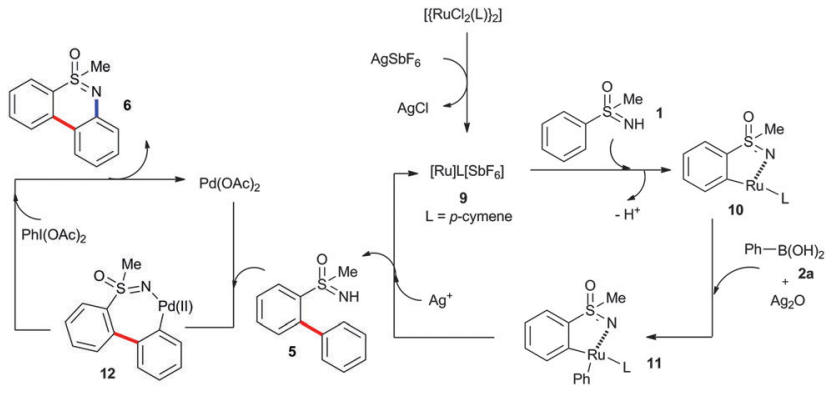

Scheme 5 Proposed mechanism.

active ruthenium species 9 for the next catalytic cycle. Another ortho arylation also takes place in a similar fashion. In the second catalytic cycle, compound 5 reacts with $\mathrm{Pd}(\mathrm{OAc})_{2}$ giving palladacycle 12. Reductive elimination of intermediate 12 in the presence of $\mathrm{PhI}(\mathrm{OAc})_{2}$ provides cyclic product 6 and regenerates the active $\mathrm{Pd}(\mathrm{OAc})_{2}$ catalyst for the next catalytic cycle. The exact role of $\mathrm{Ag}_{2} \mathrm{O}$ is not clear to us, it could be possible that the $\mathrm{AgO}^{-}$ anion acts as a base to accelerate the transmetallation of boronic acid $\mathbf{2}$ into intermediate $\mathbf{1 2}$ and the $\mathrm{Ag}^{+}$ion acts as an oxidant to oxidize $\mathrm{Ru}(0)$ to $\mathrm{Ru}(\mathrm{II})$.

In conclusion, we have described a two-step synthesis of dibenzothiazines via a ruthenium-catalyzed ortho arylation of phenyl sulfoximines with phenyl boronic acids followed by intramolecular cyclization in the presence of $\mathrm{Pd}(\mathrm{OAc})_{2}$. Chiral dibenzothiazines were prepared efficiently by using chiral phenyl sulfoximine in a similar protocol.

We thank CSIR (02(0179)/14/EMR-II), India, for support of this research. R. K. thanks CSIR for a fellowship.

\section{Notes and references}

1 Bioactive sulfoximines: (a) H. Yu, Z. Qin, H. Dai, X. Zhang, X. Qin, T. Wang and J. Fang, J. Agric. Food Chem., 2008, 56, 1135; (b) D. Lu, Y. Y. Sham and R. Vince, Bioorg. Med. Chem., 2010, 18, 2037; (c) X. Y. Chen, S. J. Park, H. Buschmann, M. De Rosa and C. Bolm, Bioorg. Med. Chem. Lett., 2012, 22, 4307; (d) For a review, see: U. Lücking, Angew. Chem., Int. Ed., 2013, 52, 9399.

2 Selected applications of chiral sulfoximines: (a) M. Haiza, J. Lee and J. K. Snyder, J. Org. Chem., 1990, 55, 5008; (b) X. Shen, W. Zhang, C. Ni, Y. Gu and J. Hu, J. Am. Chem. Soc., 2012, 134, 16999; (c) J. Brandt and H.-J. Gais, Tetrahedron: Asymmetry, 1997, 6, 909.

3 (a) M. A. M. Capozzi, C. Cardellicchio, F. Naso and P. Tortorella, J. Org. Chem., 2001, 66, 5933; (b) C. P. R. Hackenberger, G. Raabe and C. Bolm, Chem. - Eur. J., 2004, 10, 2942; (c) S. Pyne, Sulfur Rep., 1992, 12, 57; (d) C. R. Johnson, Acc. Chem. Res., 1973, 6, 341; (e) M. Gerisch, J. R. Krumper, R. G. Bergman and T. D. Tilley, J. Am. Chem. Soc., 2001, 123, 5818.

4 (a) M. Harmata, Z. Cai and Y. Chen, J. Org. Chem., 2009, 74, 5559; (b) M. Harmata, R. J. Claassen and C. L. Barnes, J. Org. Chem., 1991, 56, 5059; (c) L. Wang, D. L. Priebbenow, X. Y. Chen, F.-F. Pan and
C. Bolm, Eur. J. Org. Chem., 2015, 3338; (d) M. Harmata and N. Pavri, Angew. Chem., Int. Ed., 1999, 38, 2419.

5 (a) H.-J. Gais, Heteroat. Chem., 2007, 18, 472; (b) S. G. Pyne, Z. Dong, B. W. Skelton and A. H. White, J. Org. Chem., 1997, 62, 2337; (c) B. M. Trost and R. T. Matuoka, Synlett, 1992, 27; (d) M. Harmata and X. Hong, J. Am. Chem. Soc., 2003, 125, 5754.

6 (a) M. Harmata and N. Pavri, Angew. Chem., Int. Ed., 1999, 38, 2419; (b) M. Harmata and X. Hong, Tetrahedron Lett., 2005, 46, 3847; (c) M. Harmata, K. Rayanil, M. G. Gomes, P. Zheng, N. L. Calkins, S.-Y. Kim, Y. Fan, V. Bumbu, D. R. Lee, S. Wacharasindhu and X. Hong, Org. Lett., 2005, 7, 143; (d) M. Harmata and E. O. Schlemper, Tetrahedron Lett., 1987, 28, 5997; (e) M. Harmata, R. J. Claassen and C. L. Barnes, J. Org. Chem., 1991, 56, 5059.

7 (a) W. Dong, L. Wang, K. Parthasarathy, F. Pan and C. Bolm, Angew. Chem., Int. Ed., 2013, 52, 11573; (b) K. Parthasarathy and C. Bolm, Chem. - Eur. J., 2014, 20, 4896; (c) W. Dong, K. Parthasarathy, Y. Cheng, F. Pan and C. Bolm, Chem. - Eur. J., 2014, 20, 15732; (d) R. M. Yadav, R. K. Rit, M. Shankar and A. K. Sahoo, J. Org. Chem., 2014, 79, 6123; (e) M. Bhanuchandra, M. R. Yadav, R. K. Rit, M. R. Kuram and A. K. Sahoo, Chem. Commun., 2013, 49, 5225.

8 (a) D. Alberico, M. E. Scott and M. Lautens, Chem. Rev., 2007, 107, 174; (b) G. P. McGlacken and L. M. Bateman, Chem. Soc. Rev., 2009, 38, 2447; (c) C.-L. Sun, B.-J. Li and Z.-J. Shi, Chem. Rev., 2011, 111, 1293; (d) O. Daugulis, H.-Q. Do and D. Shabashov, Acc. Chem. Res., 2009, 42, 1074; (e) L. Ackermann, R. Vicente and A. R. Kapdi, Angew. Chem., Int. Ed., 2009, 48, 9792; $(f)$ D.-G. Yu, B.-J. Li and Z.-J. Shi, Tetrahedron, 2012, 68, 5130; $(g)$ P. B. Arockiam, C. Bruneau and P. H. Dixneuf, Chem. Rev., 2012, 112, 5879.

9 (a) S. Ueno, N. Chatani and F. Kakiuchi, J. Org. Chem., 2007, 72, 3600; (b) F. Kakiuchi, S. Kan, K. Igi, N. Chatani and S. Murai, J. Am. Chem. Soc., 2003, 125, 1698; (c) L. Ackermann, R. Vicente and A. Althammer, Org. Lett., 2008, 10, 2299; (d) P. B. Arockiam, C. Fischmeister, C. Bruneau and P. H. Dixneuf, Angew. Chem., Int. Ed., 2010, 49, 6629.

10 (a) C. G. Ravi Kiran and M. Jeganmohan, Chem. Commun., 2014, 50, 2442, references therein; (b) C. G. Ravi Kiran and M. Jeganmohan, Org. Lett. , 2012, 14, 5246; (c) J. Hubrich, T. Himmler, L. Rodefeld and L. Ackermann, Adv. Synth. Catal., 2015, 357, 474; (d) V. K. Tiwari, N. Kamal and M. Kapur, Org. Lett., 2015, 17, 1766Other metals: (e) S. Yang, B. Li, X. Wan and Z. Shi, J. Am. Chem. Soc., 2007, 129, 6066; $(f)$ C.-L. Sun, B.-J. Li and Z.-J. Shi, Chem. Commun., 2010, 46, 677; $(g)$ J. Karthikeyan, R. Haridharan and C.-H. Cheng, Angew. Chem., Int. Ed., 2012, 51, 12343; $(h)$ N. Senthikumar, K. Parthasarathy, P. Gandeepan and C.-H. Cheng, Chem. - Asian J., 2013, 8, 2175; (i) S. Oi, S. Fukita and Y. Inoue, Chem. Commun., 1998, 2439; $(j)$ K. Ueura, T. Satoh and M. Miura, Org. Lett., 2005, 7, 2229. 11 (a) C. Moessner and C. Bolm, Org. Lett., 2005, 7, 2667; (b) J. Kim, J. Ok, S. Kim, W. Choi and P. H. Lee, Org. Lett., 2014, 16, 4602; (c) N. Yongpruksa, N. L. Calkins and M. Harmata, Chem. Commun., 2011, 47, 7665; (d) M. Miyasaka, K. Hirano, T. Satoh, R. Kowalczyk, C. Bolm and M. Miura, Org. Lett., 2011, 13, 359.

12 (a) W. C. P. Tsang, R. H. Munday, G. Brasche, N. Zheng and S. L. Buchwald, J. Org. Chem., 2008, 73, 7603; (b) P. Gandeepan, C.-H. Hung and C.-H. Cheng, Chem. Commun., 2012, 48, 9379; (c) B. Li, S. Tian, Z. Fang and Z. Shi, Angew. Chem., Int. Ed., 2008, 47, 1115; (d) M.-L. Louillat and F. W. Patureau, Chem. Soc. Rev., 2014, 43, 901.

13 (a) E. Ferrer-Flegeau, C. Bruneau, P. H. Dixneuf and A. Jutand, J. Am. Chem. Soc., 2011, 133, 10161; (b) S. Warratz, C. Kornhaab, A. Cajaraville, B. Niepotter, D. Stalke and L. Accermann, Angew. Chem., Int. Ed., 2015, 54, 5513. 